\title{
KECEPATAN ADUK DAN WAKTU KONTAK OPTIMUM PEMBUATAN BIODIESEL DARI MINYAK JELANTAH
}

\author{
Dwi Kartika, Eva Vaulina, Y.D, Senny Widyaningsih, Moch. Chasani \\ Prodi Kimia, Jurusan Matematika dan Ilmu Pengetahuan Alam, \\ Fakultas Sains dan Teknik, Universitas Jenderal Soedirman \\ Jl. Dr. Soeparno Karangwangkal Purwokerto 53123 Jawa Tengah Indonesia
}

\begin{abstract}
Synthesis of biodiesel from waste cooking oil using activated natural zeolite catalyst has been done. Activation of the natural zeolite was done by refluxing with $\mathrm{HCl}$ $6 \mathrm{M}$ for $30 \mathrm{~min}$, calcining and oxydizing at $500^{\circ} \mathrm{C}$ for 2 hours, consecutively. The variation of stirring speed were $350,700,1100$ and $1200 \mathrm{rpm}$. The variation of reaction time were varied from 15, 30, 45, 60, and $120 \mathrm{~min}$. The conversion of biodiesel was determined by ${ }^{1} \mathrm{H}$ NMR spectrometer. The results showed that the optimum condition of biodiesel synthesis using esterification process were reached at $700 \mathrm{rpm}$ and 15 minutes, which gave biodiesel conversion of $100 \%$.
\end{abstract}

Keywords : waste cooking oil, biodiesel, zeolite

\section{PENDAHULUAN}

Pembuatan biodiesel telah banyak dilakukan seiring menipisnya cadangan minyak bumi dunia. Penelitian diawali Rudolf Diesel, pada tahun 1900 menciptakan mesin diesel berbahan bakar minyak nabati (minyak kacang tanah) (Knothe et al., 1997; Khan, 2002). Penelitian yang telah dilakukan merupakan tahap awal menuju komersialisasi, walaupun diperlukan pengembangan lebih lanjut dalam berbagai aspek teknis dan ekonomis (Yoeswono et al., 2007)

Biodiesel didefinisikan sebagai mono alkil ester asam lemak rantai panjang yang diturunkan dari bahan baku lemak sebagai sumber yang dapat diperbaharui, seperti minyak nabati dan lemak hewani, untuk digunakan dalam mesin diesel (ASTM, 2003 ${ }^{\mathrm{b}}$ ). Pemanfaatan biodiesel dapat mengurangi berbagai masalah, diantaranya sebagai solusi mengantisipasi krisis energi. Selain itu, sebagai upaya untuk mendorong eksplorasi bahan bakar alternatif yang ramah lingkungan (Knothe et al., 1997; Srivastava dan Prasad, 2000).

Pemanfaatan minyak jelantah sebagai bahan baku biodiesel memberikan nilai lebih, karena melimpah dan merupakan bahan yang tidak terpakai lagi. Ketika minyak goreng dipakai untuk menggoreng terjadi peristiwa oksidasi dan hidrolisis yang memecah molekul minyak menjadi asam. Konsentrasi asam lemak bebas bertambah dengan pemanasan pada suhu tinggi dan waktu yang lama selama penggorengan. Adanya asam lemak bebas dalam minyak goreng dapat menjadi ester apabila bereaksi dengan metanol, namun jika bereaksi dengan natrium atau kalium akan membentuk sabun. Adanya soda yang ada pada biodiesel dapat menghidrolisis dan memecah biodiesel menjadi asam lemak bebas (free fatty acid) yang kemudian terlarut dalam biodiesel itu sendiri. Kandungan asam lemak dalam biodiesel dapat menyumbat filter (saringan) dan dapat mengakibatkan korosi pada mesin diesel. 
Kadar asam lemak bebas dapat menyebabkan reaksi penyabunan dan menghambat pembentukan biodiesel pada reaksi transesterifikasi. Salah satu metode untuk mengatasinya dengan perlakuan awal terhadap minyak jelantah untuk mengurangi kadar asam lemak bebas sebelum dilakukan transesterifikasi. Tujuan perlakuan awal untuk mengubah asam lemak bebas menjadi alkil ester (biodiesel) melalui esterifikasi. Reaksi esterifikasi umumnya dilakukan menggunakan katalis asam sulfat, namun penggunaan katalis heterogen lebih dipertimbangkan seperti zeolit, clay, dan karbon karena kemudahan pemisahan (Pinto et al., 2005).

Wilayah Indonesia kaya akan cadangan zeolit alam yang umumnya memiliki ukuran pori tidak seragam, stabilitas termal yang tidak terlalu tinggi, dan aktivitas katalitik rendah sehingga perlu aktivasi atau modifikasi. Zeolit alam merupakan kristal aluminosilikat dengan kerangka anionik kaku berupa kanal dan rongga. Rongga tersebut umumnya berisi kation yang dapat dipertukarkan, seperti $\mathrm{Na}^{+}, \mathrm{K}^{+}$, dan $\mathrm{Ca}^{2+}$ (Kartika, 2008).
Rumus struktur zeolit berdasarkan unit sel kristal atau unit struktur terkecil dapat dinyatakan sebagai berikut :

dimana :

$$
\mathrm{M}_{\mathrm{x} / \mathrm{n}}\left\{\left(\mathrm{AlO}_{2}\right)_{\mathrm{x}}\left(\mathrm{SiO}_{2}\right)_{\mathrm{y}}\right\}_{\mathrm{w}} \mathrm{H}_{2} \mathrm{O}
$$

$\mathrm{n}=$ valensi dari kation $\mathrm{M}$.

$\mathrm{w}=$ jumlah molekul air per unit sel.

$\mathrm{x}, \mathrm{y}=$ jumlah total tetrahedral per unit sel.

Umumnya $\mathrm{y} / \mathrm{x}$ biasanya bernilai

1-5, tetapi zeolit dengan silika tinggi mempunyai harga $\mathrm{y} / \mathrm{x}$ hingga 10-100 bahkan lebih tinggi (Flanigen, 1991). Aktivasi zeolit dapat dilakukan dengan kalsinasi ataupun perlakuan asam. Zeolit alam yang telah termodifikasi atau teraktivasi dapat berperan sebagai katalis dalam pembuatan biodiesel.

Berdasarkan uraian di atas, dengan ketersediaan sumber daya alam yang melimpah baik zeolit alam maupun minyak jelantah, Indonesia mempunyai potensi dalam menekan biaya produksi untuk membuat biodiesel. Reaksi esterifikasi dan transesterifikasi dari minyak nabati dapat dilihat pada Gambar 1 dan Gambar 2.

$$
\begin{aligned}
& \mathrm{RCOOH} \\
& \text { Asam lemak }
\end{aligned}+\underset{\text { Metanol }}{\mathrm{CH}_{3} \mathrm{OH}} \stackrel{\mathrm{H}^{+}}{\rightleftharpoons} \underset{\text { Metil ester }}{\mathrm{RCOOCH}_{3}}+\underset{\text { Air }}{\mathrm{H}_{2} \mathrm{O}}
$$

Gambar 1. Reaksi esterifikasi asam lemak bebas menjadi metil ester dengan katalis asam

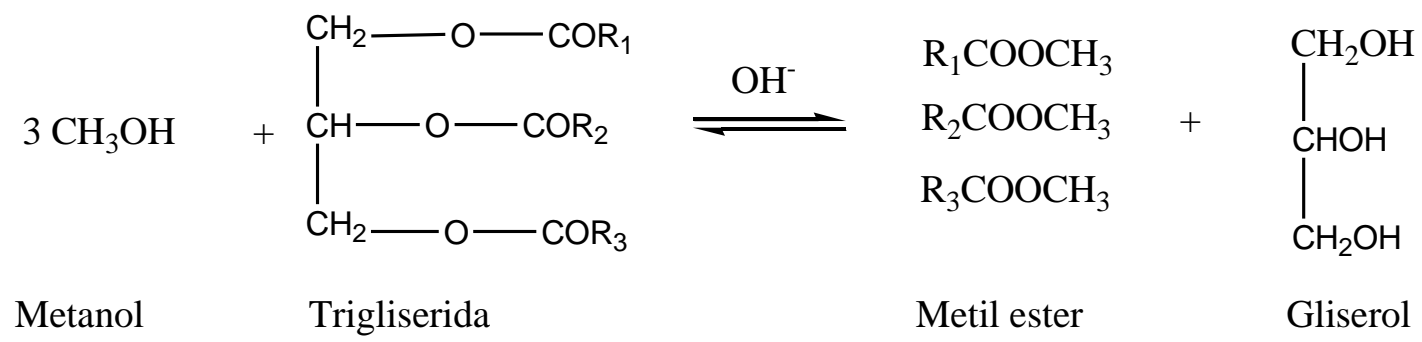

Gambar 2. Reaksi transesterifikasi trigliserida menjadi metil ester dengan katalis basa;

$\mathrm{R}_{1}, \mathrm{R}_{2}, \mathrm{R}_{3}$ merupakan asam lemak jenuh dan tidak jenuh

Penelitian ini mengkaji pembuatan biodiesel berbahan minyak jelantah dan zeolit alam sebagai sumber katalis asam reaksi esterifikasi sebelum dilakukan transesterifikasi. Variasi dilakukan terhadap kecepatan aduk dan waktu reaksi dalam proses esterifikasi. Penelitian ini bertujuan untuk mengetahui 
pengaruh kecepatan aduk dan waktu reaksi terhadap konversi biodiesel.

\section{METODE PENELITIAN Bahan dan Alat}

Bahan yang digunakan dalam penelitian adalah zeolit alam, minyak jelantah (dari rumah makan di Purwokerto), bahan kimia dari Merck terdiri atas: air bebas ion, metanol p.a, asam sulfat p.a., asam klorida (37 \%) p.a., dan $\mathrm{KOH}$ p.a. dan natrium sulfat anhidrat p.a.

Alat-alat yang digunakan dalam penelitian adalah seperangkat alat gelas laboratorium, satu set alat refluks (labu leher tiga kapasitas $500 \mathrm{~mL}$, termometer, pengaduk magnet, pemanas listrik, dan sistem pendingin), stopwatch, timbangan elektrik, penyaring 100 mesh, mortar dan cawan porselain, oven, spektrometer ${ }^{1} \mathrm{H}$ NMR (JEOL JNM-MY60) (Laboratorium Kimia Organik FMIPA UGM), X-Ray Diffractometer Shimadzu XRD-6000 (Laboratorium Kimia FMIPA UGM).

\section{Prosedur Penelitian}

\section{Aktivasi zeolit alam}

Dua ratus gram zeolit alam digerus sampai halus sehingga lolos penyaring 100 mesh kemudian dimasukkan dalam $100 \mathrm{~mL} \mathrm{HCl} 6 \mathrm{M}$ diaduk dengan pengaduk magnet selama 30 menit melalui proses refluks. Hasilnya dicuci dengan aquades hingga $\mathrm{pH}$ netral, kemudian dikeringkan (oven) dan dikalsinasi pada suhu $400{ }^{\circ} \mathrm{C}$, selanjutnya diayak dengan pengayak 100 mesh. Zeolit yang diperoleh untuk selanjutnya disebut zeolit alam aktif atau ZAH. Jenis komposisi dan kristalinitas zeolit dianalisis dengan $X$-Ray Diffractometer.

\section{Esterifikasi dan transesterifikasi minyak jelantah}

Sebelum dilakukan esterifikasi dan transesterifikasi, minyak jelantah dipanaskan pada suhu $100-120^{\circ} \mathrm{C}$ untuk menguapkan air. Setelah dipanaskan, disaring untuk memisahkan pengotor padat yang berukuran besar. Selanjutnya dipisahkan lagi lapisan minyak yang cair dengan corong pemisah. Esterifikasi dan transesterifikasi minyak jelantah dilakukan pada labu leher tiga kapasitas $500 \mathrm{~mL}$, yang dilengkapi dengan tempat katalis, pemanas listrik, termometer, pengaduk magnet, dan sistem pendingin.

Langkah esterifikasi dimulai dari katalis ZAH dan metanol dimasukkan dalam labu leher tiga yang berisi minyak jelantah. Sistem minyak jelantah dan metanol suhunya dibuat sama sebelum pencampuran. Proses esterifikasi dibuat variabel proses berupa kecepatan pengadukan dan waktu reaksi. Cepat pengadukan diatur $350 \mathrm{rpm}$ (skala I), 700 rpm (skala II), $1100 \mathrm{rpm}$ (skala III) dan $1200 \mathrm{rpm}$ (skala IV) pada hotplate strirrer. Kondisi operasi yang dibuat tetap yaitu menggunakan katalis ZAH 3\% (b/b), suhu reaksi $60{ }^{\circ} \mathrm{C}$, waktu reaksi 15 menit, dan rasio molar minyak metanol 1:9.

Waktu reaksi divariasi pada 15, 30, 45, 60, 120 menit. Kondisi operasi yang dibuat tetap yaitu katalis ZAH 3\% (b/b), suhu reaksi $60{ }^{\circ} \mathrm{C}$, kecepatan aduk 700 rpm, dan rasio molar minyak metanol 1:9.

Hasil esterifikasi berupa cairan dipisahkan dari padatannya, kemudian bagian cair disentrifuge untuk memisahkan pengotor padatan yang terlarut. Setelah disaring, ekstrak yang diperoleh dilakukan destilasi untuk menguapkan dan menghilangkan adanya air dan metanol yang berlebih.

Selanjutnya dilakukan proses transesterifikasi dengan katalis basa $\mathrm{KOH}$ dengan rasio molar minyak-metanol 1:6. Sebanyak 150 g minyak dimasukkan dalam labu leher tiga, kemudian dirangkai dengan sistem pendingin. Sejumlah 33,49 g metanol dan $1 \%$ (b/b) $\mathrm{KOH}$ yang telah dihomogenkan dituang ke dalam labu leher tiga tersebut, dan 
pengaduk magnet dihidupkan. Suhu minyak maupun campuran metanol $\mathrm{KOH}$ disamakan pada $60-63^{\circ} \mathrm{C}$ sebelum pencampuran. Waktu reaksi dicatat sejak pengaduk magnet dihidupkan. Setelah reaksi berjalan 60 menit, pengadukan dihentikan, campuran dituang dalam corong pemisah, dibiarkan terjadi pemisahan selama 2 jam pada suhu kamar. Lapisan metil ester dipisahkan dari lapisan gliserol, selanjutnya sisa metanol dalam lapisan metil ester diuapkan. Sisa katalis dan gliserol dalam metil ester dihilangkan dengan pencucian air berulang kali, sampai diperoleh lapisan air yang jernih. Metil ester dikeringkan dengan penambahan $\mathrm{Na}_{2} \mathrm{SO}_{4}$ anhidrat.

Sebelum dan setelah dilakukan transesterifikasi, minyak dianalisis dengan spektrometer ${ }^{1} \mathrm{H}$ NMR untuk menentukan konversi biodieselnya. Persentase konversi metil ester dianalisis dengan spektrometer ${ }^{1} \mathrm{H}$ NMR (60 MHz, solvent $\left.\mathrm{CDCl}_{3}\right)$. Konversi metil ester (yang dinyatakan sebagai konsentrasi metil ester) ditentukan dengan persamaan (1). Persentase sisa trigliserida (TG) dalam produk ditentukan dengan persamaan (2). Sisa TG dalam produk dengan satuan persentase berat ditentukan dengan persamaan (3).

$$
\begin{aligned}
& \mathrm{C}_{\mathrm{ME}}, \%=100 \times \frac{5 \mathrm{I}_{\mathrm{ME}}}{5 \mathrm{I}_{\mathrm{ME}}+9 \mathrm{I}_{\mathrm{TG}}} \\
& \mathrm{C}_{\mathrm{TG}}, \%=100-\mathrm{C}_{\mathrm{ME}} \\
& \mathrm{TG}, \% \mathrm{~b} / \mathrm{b}=\frac{\mathrm{C}_{\mathrm{TG}} \times \mathrm{MW}_{\mathrm{TG}} \times \mathrm{d}_{\mathrm{TG}}}{\left(\mathrm{C}_{\mathrm{TG}} \times \mathrm{MW}_{\mathrm{TG}} \times \mathrm{d}_{\mathrm{TG}}\right)+\left(\mathrm{C}_{\mathrm{ME}} \times \mathrm{MW}_{\mathrm{ME}} \times \mathrm{d}_{\mathrm{ME}}\right)}
\end{aligned}
$$

di mana $\mathrm{C}_{\mathrm{ME}}=$ konversi metil ester (\%), $\mathrm{I}_{\mathrm{ME}}=$ nilai integrasi puncak metil ester $(\%), \quad \mathrm{I}_{\mathrm{TG}}=$ nilai integrasi puncak trigliserida $(\%), \mathrm{C}_{\mathrm{TG}}=$ trigliserida yang tidak terkonversi $(\%), \mathrm{MW}_{\mathrm{TG}}=$ berat molekul trigliserida $\left(\mathrm{g} . \mathrm{mol}^{-1}\right), \mathrm{MW}_{\mathrm{ME}}=$ berat molekul metil ester $\left(\mathrm{g} \cdot \mathrm{mol}^{-1}\right), \mathrm{d}_{\mathrm{TG}}=$ densitas trigliserida $\left(\mathrm{kg} . \mathrm{m}^{-3}\right)$ dan $\mathrm{d}_{\mathrm{ME}}=$ densitas metil ester $\left(\mathrm{kg} . \mathrm{m}^{-3}\right)$.

\section{HASIL DAN PEMBAHASAN Karakteristik Zeolit}

Analisis dengan XRD dilakukan secara kualitatif dengan membandingkan difraktogram sampel zeolit dengan difraktogram zeolit alam standar seperti mordenit, klinoptilolit, dan kuarsa. Hasil analisis sampel zeolit dengan XRD diperoleh posisi sudut difraksi (2 $\theta$ ) yang menggambarkan jenis kristalnya. Tabel 1 mengindikasikan bahwa sampel zeolit memiliki kandungan mineral zeolit jenis mordenit, klinoptilolit, dan kuarsa. Difraktogram zeolit alam yang diperoleh dari XRD ditunjukkan dalam Gambar 3.

Tabel 1 Identifikasi posisi sudut difraksi (20) pada difraktogram XRD sampel katalis dengan zeolit alam standar

\begin{tabular}{ll|l}
\hline \multirow{2}{*}{ Jenis Zeolit } & \multicolumn{3}{l}{$2 \theta$} \\
\cline { 2 - 4 } & Zeolit alam sampel & Zeolit alam standar ${ }^{*}$ \\
\hline Mordenit & 6,$41 ; 8,44 ; 9,76 ; 13,44 ; 13,9 ;$ & 6,$51 ; 8,61 ; 9,77 ; 13,45 ; 13,83 ;$ \\
& 14,$56 ; 15,26 ; 19,65 ; 23,13 ; 25,64 ;$ & 14,$59 ; 15,3 ; 19,61 ; 23,16 ; 25,63 ;$ \\
& 26,$28 ; 27,75 ; 35,00$ dan 35,63 & 26,$25 ; 27,67 ; 35,12$ dan 35,61 \\
\hline Klinoptilolite & 11,$16 ; 17,36 ; 19,02 ; 20,10 ; 22,29 ;$ & 11,$19 ; 17,36 ; 19,10 ; 20,40 ;$ \\
& 23,$66 ; 25,02 ; 26,28 ; 30,05$ dan & 22,$36 ; 23,81 ; 25,05 ; 26,29 ;$ \\
& 48,43 & 30,05 dan 48,49 \\
\hline Kuarsa & 20,$86 ; 26,66$ dan 36,52 & 20,$86 ; 26,65$ dan 36,56 \\
\hline Sumber : ${ }^{*}$ & Treacy dan Higgins, 2001 &
\end{tabular}




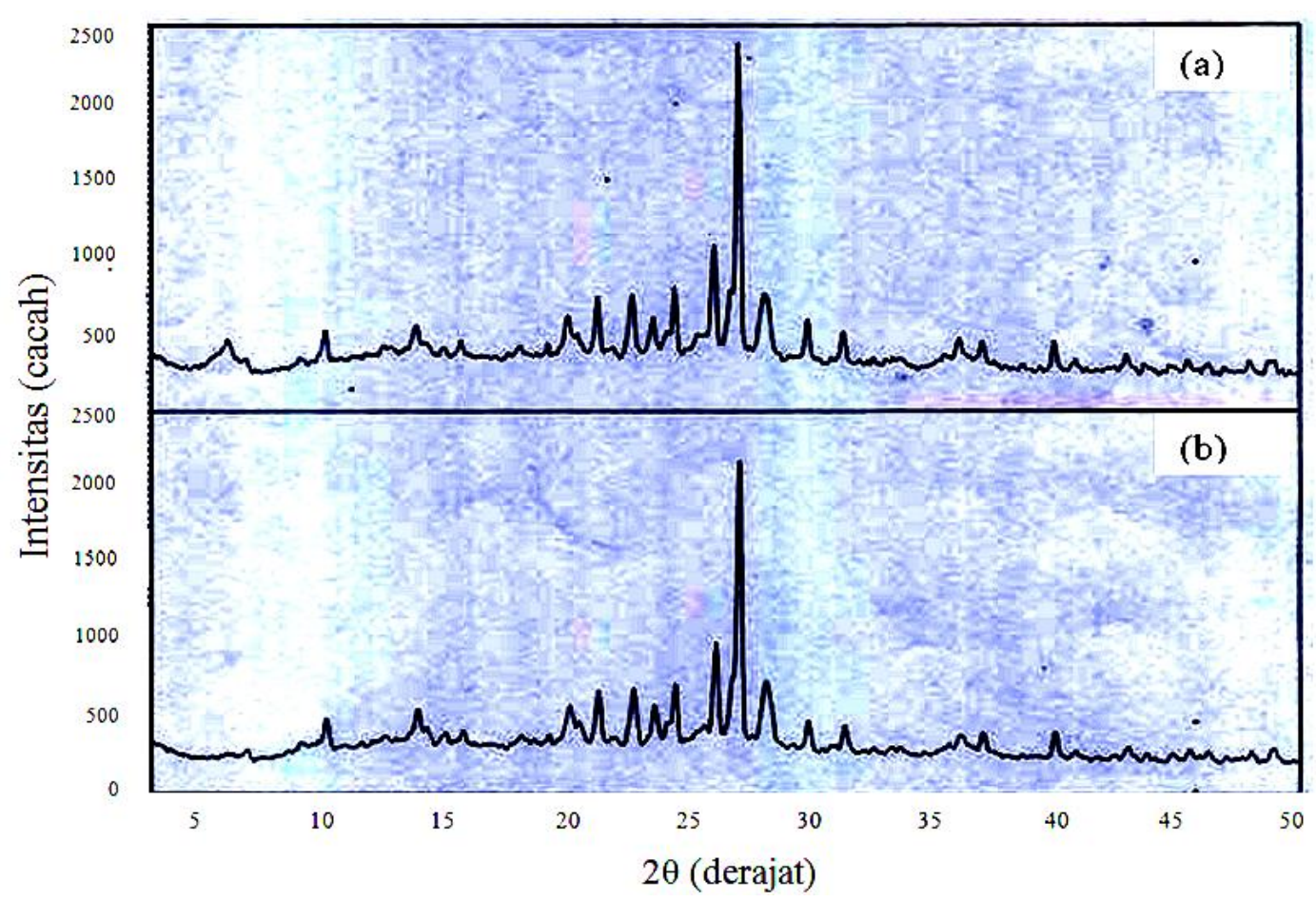

Gambar 3. Difraktogram (a) zeolit alam, dan (b) zeolit alam teraktivasi $\mathrm{HCl} 6 \mathrm{M}$, kalsinasi pada $400{ }^{\circ} \mathrm{C}$

Berdasarkan difragtogram XRD menunjukkan berkurangnya intensitas puncak mordenit dan klinoptilolite pada difraktogram setelah proses aktivasi baik dengan $\mathrm{HCl}$. Puncak pada $2 \theta=26,66$ yang hilang dari klinoptilolite bukanlah puncak utama. Perlakuan $\mathrm{HCl}$ menyebabkan penghilangan pengotor klinoptilolite dan penurunan kristalinitas mordenit tetapi tidak sampai merusak struktur kristal mordenit dalam zeolit alam dan dimungkinkan mengubah zeolit menjadi lebih amorf.

\section{Pengaruh Kecepatan Aduk terhadap Konversi Biodiesel}

Reaktan-reaktan yang terlibat dalam pembuatan biodiesel merupakan bahan yang tidak saling campur, sehingga pada awal reaksi reaktan-reaktan yang ada membentuk dua fasa. Pada kondisi ini transfer massa relatif rendah, yang mengakibatkan laju reaksi menjadi lambat. Saat metil ester sudah terbentuk, maka metil ester tersebut dapat bertindak sebagai pelarut reaktan-reaktan tersebut sehingga terbentuk sistem satu fasa. Dengan demikian kecepatan pengadukan berpengaruh besar saat tahap awal reaksi dan pengaruhnya menjadi tidak signifikan setelah sistem menjadi satu fasa.

Gambar 4 menunjukkan bahwa pada kecepatan aduk 350 rpm konversi biodiesel 93,69\%, kemudian peningkatan intensitas pengadukan pada $700 \mathrm{rpm}$ berpengaruh pada cepatnya tumbukan antar partikel reaktan sehingga kecepatan terbentuknya produk meningkat yang ditandai dengan konversi biodiesel mencapai optimum sebesar $100 \%$.

Intensitas pengadukan yang ditingkatkan melebihi $700 \mathrm{rpm}$ menjadi tidak signifikan dan laju reaksi lebih dipengaruhi oleh suhu (Noureddini dan Zhu, 1997). Keadaan ini menyebabkan konversinya berpeluang turun kembali. Penurunan konversi biodiesel juga diakibatkan oleh munculnya produk samping yang semakin banyak berupa air. Prinsip Le Chatelier menerangkan bahwa apabila terjadi penambahan 
produk dalam suatu proses kesetimbangan maka reaksi akan berjalan kearah kiri untuk menetralkan pengaruh

penambahan produk, caranya dengan jalan mereaksikan $\mathrm{H}_{2} \mathrm{O}$ dan metil ester menjadi reaktan kembali.

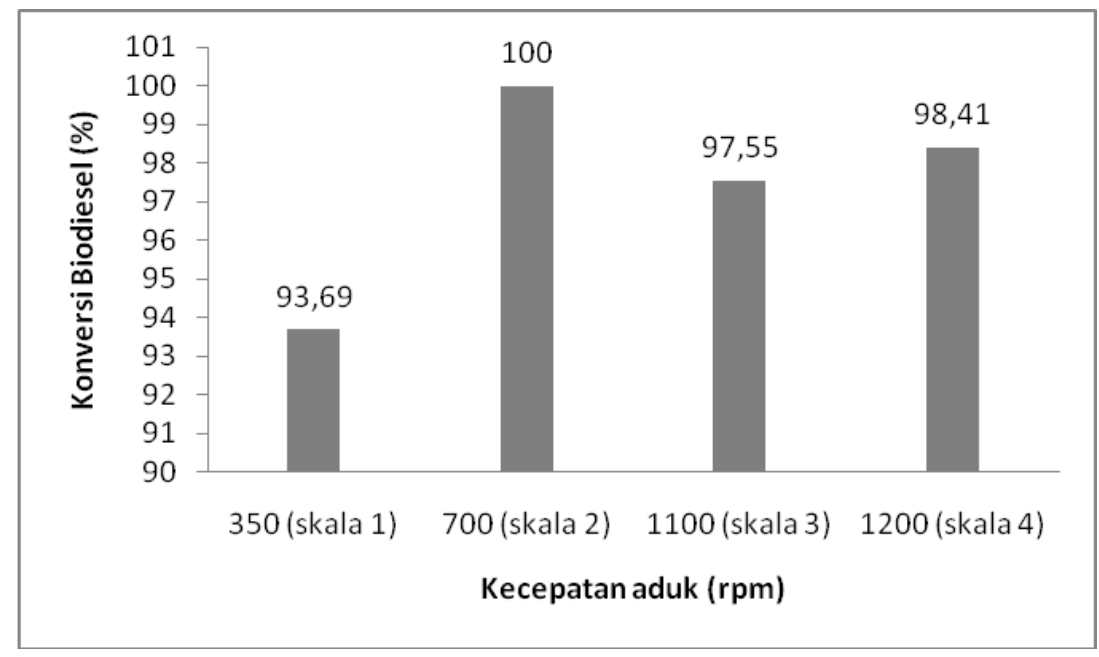

Gambar 4. Hubungan kecepatan aduk terhadap konversi biodiesel dari minyak jelantah menggunakan katalis zeolit alam teraktifasi $\mathrm{HCl}$ pada reaksi esterifikasi dengan waktu reaksi 15 menit

\section{Pengaruh Waktu Reaksi terhadap Konversi Biodiesel}

Pada umumnya semakin lama waktu reaksi konversi yang dihasilkan semakin besar. Hal ini disebabkan karena lamanya waktu reaksi memberikan kesempatan yang besar bagi molekulmolekul reaktan untuk saling bertumbukan dan bereaksi. Kondisi ini tidaklah demikian, pada waktu reaksi 1560 menit memberikan konversi biodiesel yang hampir stabil antara 98,41-100\% (Gambar 5). Waktu reaksi 15 menit dapat dikatakan waktu reaksi optimum apabila dibandingkan dengan 30, 45, dan 60 menit karena waktu terpendek namun memberikan konversi optimum.

Waktu reaksi diperlama sampai 2 jam mengakibatkan konversinya turun. Waktu reaksi dipengaruhi oleh kecepatan aduknya. Kecepatan aduk $700 \mathrm{rpm}$ pada pembuatan biodiesel dalam penelitian ini termasuk tinggi. Berdasarkan penelitian terdahulu kecepatan aduk yang disarankan untuk menghasilkan biodiesel dalam kisaran 80, 100, 125 rpm (May, 2004), dan $350 \mathrm{rpm}$ (Foon et al., 2004).

Menurut May (2004) kecepatan aduk yang tinggi membutuhkan waktu reaksi yang lebih pendek agar tercapai konversi optimum, 50 menit untuk 80 rpm, 21 menit untuk $100 \mathrm{rpm}$, dan 14 menit untuk $125 \mathrm{rpm}$. Foon et al (2004) melaporkan konversi biodiesel mencapai optimum sebesar $99 \%$ dengan kecepatan pengadukan $350 \mathrm{rpm}$ dengan waktu reaksi 7 menit. Penurunan konversi biodiesel seiring waktu reaksi yang diperlama sampai 2 jam pada penelitian dimungkinkan karena penggunaan kecepatan aduk besar sehingga waktu reaksi efektif menjadi pendek. 


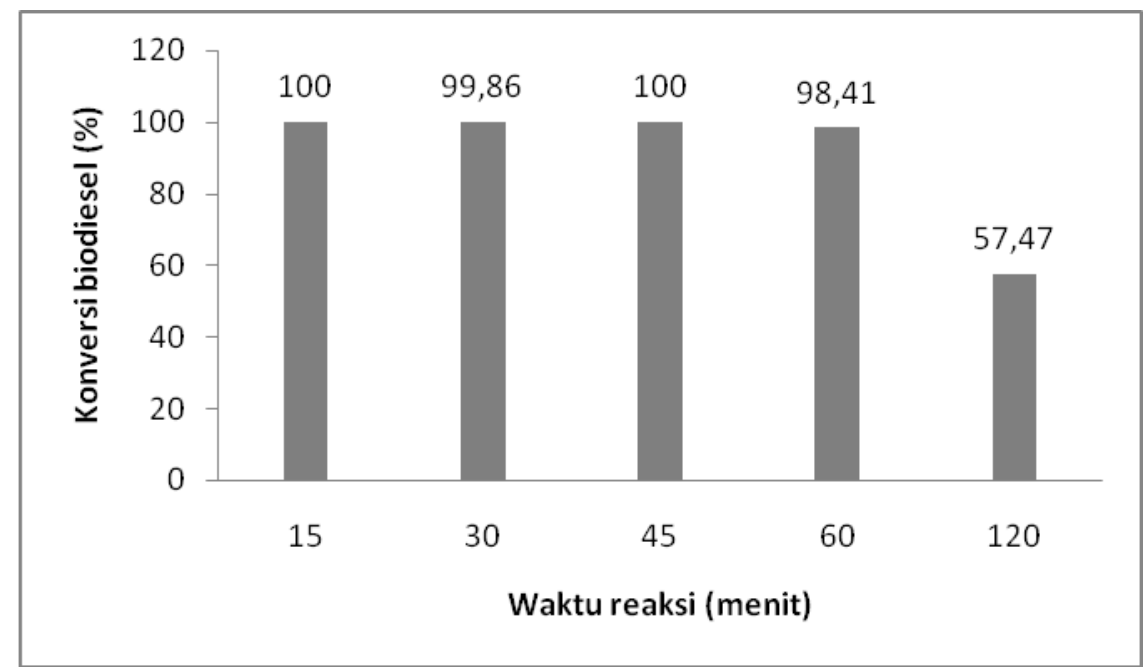

Gambar 5. Hubungan waktu reaksi dengan konversi biodiesel dari minyak jelantah menggunakan katalis zeolit alam teraktifasi $\mathrm{HCl}$ pada reaksi esterifikasi dengan kecepatan aduk $700 \mathrm{rpm}$

\section{SIMPULAN}

Berdasarkan hasil penelitian dapat disimpulkan bahwa zeolit aktif dapat digunakan sebagai katalis dalam proses pra-transesterifikasi dalam pembuatan biodiesel. Kondisi optimal yang dicapai pada kecepatan pengadukan $700 \mathrm{rpm}$ dan waktu reaksi 15 menit pada reaksi esterifikasi sebelum transesterifikasi dengan konversi biodiesel sebesar $100 \%$.

\section{UCAPAN TERIMA KASIH}

Penulis mengucapkan terimakasih kepada Universitas Jenderal Soedirman yang telah membiayai penelitian ini melalui DIPA BLU Unit Jurusan MIPA FST UNSOED tahun 2010. Penulis juga mengucapkan terimakasih kepada Agus Dwi Harso dan Oki Isdiyanto yang telah membantu dalam pengambilan data.

\section{DAFTAR PUSTAKA}

ASTM, 2003 ${ }^{\mathrm{b}}$, Annual Book of ASTM Standards, 5, 05.04, ASTM International, West Conshohocken.
Flanigen, E.M., 1991, Zeolit and Molecular Sieve A Historial Perspective, Elsevier Science Publishers B.V., New York.

Foon, C. S., C. Y. May, M.A. Ngan dan C.C. Hock, 2004, Kinetics Study on Transesterification of Palm Oil, J. Oil Palm Res., 16, 2, 19-29

Kartika, D., 2008, Hidrogenasi Katalitik Metil Palmitat Menjadi Setil Alkohol dengan Katalis Ni/NZSiA. Tesis. FMIPA Universitas Gadjah Mada, Yogyakarta. (Tidak dipublikasikan)

Khan, A. K., 2002, Research into Biodiesel, Kinetics \& Catalyst Development, Department of Chemical Engineering, The University of Queensland, Brisbane.

Knothe, G., 2000, Monitoring a Progressing Transesterification Reaction by Fiber-Optic Near Infrared Spectroscopy with 
Correlation to ${ }^{1} \mathrm{H} \quad$ Nuclear Magnetic Resonance Spectroscopy, J. Am. Oil Chem. Soc., 77, 9483, 489-493.

Knothe, G., R. O. Dunn, and M. Bagby, 1997, Biodiesel: The Use of Vegetable Oils and Their Derivatives as Alternative Diesel Fuels, Fuels and Chemicals from Biomass, ACS Symposium Series, $\mathrm{V}, 666$.

May, C. Y., 2004, Transesterification of Palm Oil: Effect of Reaction Parameters, J. Oil Palm Res., 16, 2, $1-11$.

Noureddini, H. dan D. Zhu, 1997, Kinetics of Transesterification of Soybean Oil, J. Am. Oil Chem. Soc., 74, 11, 1457-1463.

Pinto, A. C., L. L. N. Guarieiro, M. J. C. Rezende, N. M. Ribeiro, E. A. Torres, W. A. Lopes, P. A. Pereira, and J. B. Andrade, 2005, Biodiesel: An Overview, J. Braz. Chem. Soc., 16, 6B, 1313-1330.
Srivastava, A. and R. Prasad, 2000, Triglycerides-based diesel fuels, Renewable Sustainable Energy Rev., 4, 111-133.

Treacy, M.M.J., and J.B. Higgins, 2001, Collection of Simulated XRD Powder Patternsfor Zeolites, Elsevier, Amsterdam.

Yoeswono, Triyono, and I. Tahir, 2007, The Use of Ash of Palm Empty Fruit Bunches as A Source of Base Catalyst for Synthesis of Biodiesel from Palm Kernel Oil. Proceeding of International Conferences on Chemical Sciences (ICCS-2007), Yogyakarta-Indonesia, 24-26 May 2007. 